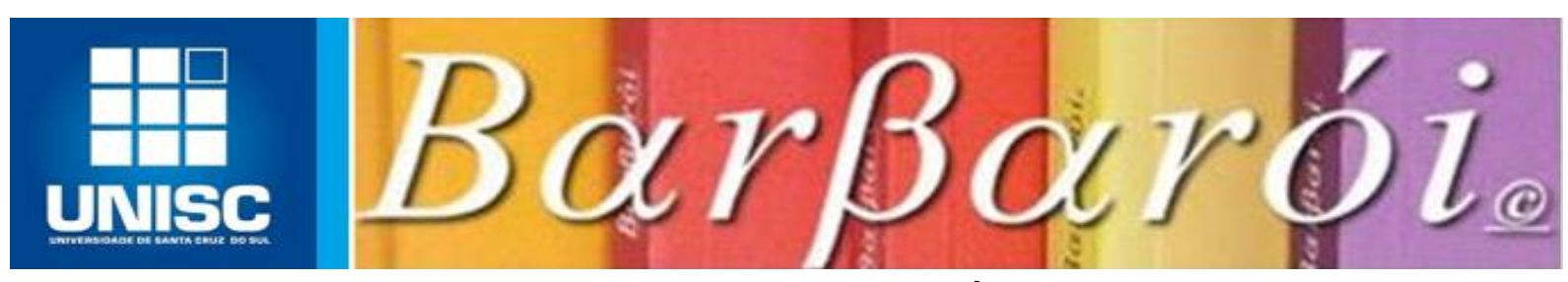

\title{
GESTAÇÃO PATERNA: UMA EXPERIÊNCIA SUBJETIVA
}

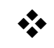 \\ Mariana Gouvêa Matos \\ Pontifica Universidade Católica do Rio de Janeiro - PUC-Rio - Brasil \\ Andrea Seixas Magalhães \\ Pontífica Universidade Católica do Rio de Janeiro - PUC-Rio - Brasil \\ Terezinha Féres-Carneiro \\ Pontífica Universidade Católica do Rio de Janeiro - PUC-Rio - Brasil \\ Rebeca Nonato Machado \\ Pontífica Universidade Católica do Rio de Janeiro - PUC-Rio - Brasil

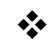

\section{Resumo:}

O presente artigo é parte de uma pesquisa mais ampla sobre as experiências subjetivas na transição para a paternidade. Foram entrevistados 8 pais, residentes da cidade do Rio de Janeiro. O objetivo deste estudo foi investigar as experiências subjetivas dos homens durante a gestação de suas parceiras. As entrevistas foram transcritas e submetidas ao método de análise de conteúdo, na modalidade categorial temática. Os resultados apontam para a intensificação do envolvimento dos pais durante a gestação, ao mesmo tempo em que tal participação esbarra nos limites do corpo, não sendo possível para os homens elaborar as mudanças decorrentes da transição para a paternidade por meio de ritualizações corporais. A ultrassonografia apareceu como uma ferramenta importante para a construção da imagem mental do bebê, constituindo-se como possibilidade de elaboração das mudanças que ocorrem no psiquismo dos pais.

Palavras-chave: Paternidade; pai; gestação; transição para parentalidade.

\section{Introdução:}

Dentre as significativas mudanças recentes ocorridas nas sociedades industrializadas, ressaltam-se aquelas relacionadas às funções atribuídas ao pai. $\mathrm{O}$ valor social conferido à figura paterna vem sofrendo modificações, agregando a noção de um pai que tem maior participação na vida familiar e afetiva, que partilha com a mulher tanto o âmbito público como o âmbito privado. O exercício da paternidade tem ocorrido de forma mais participativa e as demandas sociais passaram a apontar para o envolvimento do pai no cuidado e na criação dos filhos desde muito cedo, quando ainda bebês (CÚNICO \& ARPINI, 2013; GONÇALVES \& BOTTOLI, 2016; VIEIRA ET AL., 2014; VIEIRA \& NASCIMENTO, 2014; VIEIRA \& SOUZA, 2010). 
Concomitantemente às mudanças sociais do papel masculino, vem sendo possível observar nos grandes centros urbanos contemporâneos a emergência da Síndrome de Couvade. A síndrome é caracterizada pela vivência de modificações no corpo dos homens, com a presença de alguns sintomas físicos sem explicação fisiológica, manifestados involuntariamente pelos homens/pais durante a gestação de suas parceiras (FERREIRA, MARTENDAL, SANTOS, BIROLO \& LOPES, 2014; JAGER \& BOTTOLI, 2011; MARTINI, PICCININI \& GONÇALVES, 2010).

A cultura ocidental contemporânea parece ter possibilitado o reconhecimento, ou talvez, até mesmo, o aparecimento de vivências corporais semelhantes às da parceira nos homens cujas mulheres estão grávidas. No campo dos estudos de gênero, questiona-se o aprisionamento aos papéis sexuais, anunciando-se a possibilidade de transição entre os polos masculino e feminino por um mesmo sujeito na contemporaneidade. A expressão "casal grávido" (MALDONADO, NAHOUM \& DICKSTEIN, 1985; SALEM, 1987/2007), que passou a ser empregada em determinados extratos sociais, é um forte demonstrativo da legitimação do corpo do homem afetado pelo processo gestacional. Campos (2006) aponta para a imposição contemporânea de que "não basta ser pai, tem que engravidar" (p.155).

Contudo, na mesma medida em que as vivências que surgem no corpo do homem durante a gestação de suas mulheres parecem indicar flexibilização dos padrões de gênero, estas são enquadradas na categoria de síndrome, marcando a noção de desvio. Apesar de a noção de síndrome ser referida a um conjunto de sinais e sintomas, que não necessariamente indicam doença, mas uma condição, no imaginário social a palavra síndrome remete ao campo da patologia. Ao mesmo tempo em que o homem "grávido" parece explicitar no corpo uma autorização social para circular no domínio do feminino, constrói-se um dispositivo que patologiza tal processo. Dessa forma, a Síndrome de Couvade parece apontar tanto para a problematização quanto para a legitimação de um modelo de gênero há séculos disseminado no ocidente. A possibilidade de transitar entre os domínios masculino e feminino - ainda que aparente no discurso dos sujeitos - parece não ser dominante, principalmente quando referida ao corpo masculino.

O termo couvade foi cunhado em 1865 pelo antropólogo Tylor, e foi referido a um ritual - que garantia a legitimidade da criança, estabelecendo quem era seu pai - no qual o homem simulava um parto simultaneamente ao parto da mulher, a fim de atrair os espíritos do mal para sua cabana e proteger a mãe da ira dos mesmos (MARTINI ET AL., 2010; RAPHAEL-LEFF, 1993). 
A Síndrome de Couvade, versão ocidental do ritual, foi denominada pelos psiquiatras Trethowan e Conlon, em 1965, e inclui sintomas como náuseas, vômitos, perda de apetite, dores de cabeça, insônia, dores de dente, desejos por alimentos e aumento de peso (FERREIRA, LEAL \& MAROCO, 2010; FERREIRA ET AL., 2014; MARTINI ET AL., 2010; PARSEVAL, 1986; RAPHAEL-LEFF, 1993). Alguns autores (BORNHOLDT, WAGNER \& STAUDT, 2007; PARSEVAL, 1986; RAPHAEL-LEFF, 1993; SOIFER, 1980) referem-se à síndrome como uma expressão somática da ansiedade decorrente do processo de transição para a parentalidade. Neste sentido, estaria relacionada a fatores emocionais, referentes à identificação do homem/pai com a gestante e com o feto (RAPHAEL-LEFF, 1993), bem como à sua ambivalência em relação à paternidade (BORNHOLDT et al., 2007).

Assim, a postulação da Síndrome de Couvade propicia tanto a discussão acerca da função social que tal inscrição no corpo masculino desempenha, quanto aponta para o campo das vivências decorrentes do processo de tornar-se pai. Segundo Parseval (1986), há uma negação do corpo do pai na cultura ocidental, que faz com que os homens não consigam estabelecer nenhuma ligação consciente entre os sintomas por eles apresentados e a transição para a paternidade. A autora aborda a síndrome como uma couvade "em surdina" (p.60), na medida em que passa despercebida pelos pais e pelo meio social. Como não são socialmente permitidas, tais manifestações no corpo do homem não são percebidas em nível consciente.

No âmbito subjetivo, Houzel (2004) afirma que a Síndrome de Couvade, assim como os distúrbios de conduta e as psiconeuroses decorrentes da transição para a paternidade, aponta para mudanças no psiquismo paterno decorrentes de tal transição. O processo de tornar-se pai envolve o confronto com transformações identificatórias profundas - devido à reatualização de conflitos antigos - e constitui uma crise de identidade, semelhante à da adolescência (CAMPOS, 2006; JAGER \& BOTTOLI, 2011). Neste sentido, para o autor, a Síndrome de Couvade é um indicador das mudanças que estão ocorrendo no psiquismo paterno em decorrência da transição para a parentalidade.

Dessa forma, os sintomas da referida síndrome parecem apontar para a necessidade de aproximação da gestação pelo homem, no sentido de contribuir para o processo elaborativo das mudanças psíquicas que estão em curso. As vivências fisiológicas semelhantes às da gestante poderiam ser, então, um recurso utilizado por alguns homens para elaborar a transição para paternidade. Não há, contudo, autorização social para os homens se utilizarem do recurso ritualístico da couvade, posto que os sintomas aparecem de forma involuntária, sendo produzidos inconscientemente. De acordo com Raphael-Leff (1993), é pela falta de ritualização da transição para a paternidade na atualidade que os sintomas da síndrome 
aparecem. Segundo o autor, os sintomas podem surgir como uma manifestação de fantasias hostis dos pais em relação a seus bebês. Tal fenômeno aponta para a necessidade de os pais poderem de alguma forma ritualizar as mudanças que estão se dando em seus psiquismos, a fim de exercerem as atuais demandas de participação paterna.

Tomando como base a literatura psicanalítica, a Síndrome de Couvade é referida a sentimentos latentes do Complexo de Édipo, sendo o corpo via de manifestação de antigos conflitos. A partir da união conjugal pode surgir o desejo de ter um filho e, quando tal desejo é concretizado, o homem/pai reage à sua nova condição e às mudanças de postura de sua parceira, reativando vivências de inveja e de exclusão da relação edípica com seus pais que permaneceram recalcadas no período de latência. Na medida em que a barriga começa a crescer e a mulher começa a adquirir aspecto de grávida, tais sentimentos começam a ser experimentados pelo pai (FIGUEIREDO \& MARQUES, 2011; PARSEVAL, 1986; RAPHAEL-LEFF, 1993; SOIFER, 1980).

$\mathrm{Na}$ infância, o pai tem a função de barrar os impulsos incestuosos do filho voltados para a mãe e, quando isso ocorre, o menino se sente excluído, principalmente devido às experiências referentes à cena primária. $\mathrm{Na}$ gestação parece ocorrer algo semelhante, promovendo a revivência do período edípico. Antes da gravidez, os membros do casal nutriam-se afetivamente um ao outro com exclusividade. Com as mudanças psíquicas maternas e a entrada do terceiro, que começa a se fazer presente na medida em que a barriga cresce, o pai passa a sentir, de certo modo, o bebê como interditor da relação do casal. Desse modo, o homem atualiza sua vivência de estar de fora em uma composição triangular (CAMPOS, 2006; MALDONADO ET AL., 1985).

Ao mesmo tempo, o sentimento de exclusão surge em oposição ao sentimento de completude da mulher: o homem se sente excluído, pois sua parceira, narcisicamente, volta suas atenções para o bebê, que parece ser uma extensão dela mesma (MALDONADO ET AL., 1985; PARSEVAL, 1986). A mulher passa a se sentir completa com a gestação, geralmente investindo mais na sintonia com o feto do que com o marido, o que pode acarretar em diminuição do desejo sexual (CAMPOS, 2006). O casal passa de uma relação dual gratificante para uma relação triádica. A futura mãe começa a viver uma relação fantasmática com seu futuro bebê, e vai progressivamente investindo nessa relação e diminuindo seu investimento no mundo externo.

Para ambos os pais a experiência da parentalidade evoca sentimentos provenientes de sua própria infância, especialmente do momento no qual tiveram que partilhar sua mãe com o mundo. Porém, invariavelmente, a mãe pode reevocar essa experiência enquanto parte da 
díade que se dissolverá, ao passo que o pai se deparará com os sentimentos de perda e exclusão desde o princípio, até que na nova família ele possa encontrar um lugar a partir da reestruturação da dinâmica familiar (JAGER \& BOTTOLI, 2011; ZORNIG, 2010). A capacidade de se adaptar a essa nova configuração está, de acordo com Pincus e Dare (1978), diretamente relacionada com a forma como esses indivíduos passaram pela mesma situação na infância.

A gravidez gera no homem um estado de ansiedade que pode assumir diversas expressões, como rejeitar a esposa, proteger a mesma de forma exagerada, ou desenvolver certa tendência a submeter-se a ela, convivendo com seu despotismo. As fantasias inconscientes subjacentes a tais sensações estão relacionadas ao conflito edipiano, especialmente ao ressentimento em relação à gravidez da própria mãe (real ou fantasiada), às sensações de exclusão e à inveja daquilo que a mulher tem e ele não (SOIFER, 1980). A inveja do homem no período gestacional refere-se tanto à condição da mulher diante da procriação, à sua capacidade de gestar o bebê, quanto ao lugar em que o bebê que está sendo gestado ocupa dentro da mãe (CAMPOS, 2006; MALDONADO ET AL., 1985; PARSEVAL, 1986; RAPHAEL-LEFF, 1993; ZORNIG, 2010).

A inveja do homem com relação à gravidez pode se manifestar de forma consciente ou não. Caso apareça conscientemente, adquire características elaborativas de antecipação do filho. O homem demanda de sua companheira que lhe explique as sensações geradas com o movimento do bebê e se empenha em percebê-las (SOIFER, 1980). Por outro lado, inconscientemente, a inveja se exprime por meio da hostilidade, da indiferença, da rejeição sexual, ou de sintomas psicossomáticos (MALDONADO et al., 1985).

Os sentimentos de exclusão e inveja revividos pelo homem/pai podem ser expressos pela via fisiológica, com o objetivo de aliviar as tensões impostas pelos conflitos que estavam latentes no inconsciente. Nesse sentido, a Síndrome de Couvade é abordada como sendo uma expressão psicossomática decorrente do esforço em solucionar o conflito edipiano (CAMPOS, 2006; RAPHAEL-LEFF, 1993).

Piccinini, Levandowski, Gomes, Lindenmeyer e Lopes (2009) ressaltam que os sentimentos e conteúdos inconscientes dos pais são mais mobilizados na medida em que os homens vivenciam a gestação de forma mais próxima. Nesse sentido, pontuam que as projeções inconscientes, em relação ao bebê, dos pais que têm alto nível de envolvimento com a gestação podem ser de natureza tão primitiva quanto as das mulheres.

Contudo, as diferenças entre maternidade e paternidade existem e precisam ser consideradas. Apesar de existir uma tendência de maior inclusão do pai na gestação, a 
experiência da gravidez é, sem dúvidas, diferente para homens e mulheres. Os homens não sofrem mudanças drásticas em seus corpos e, tampouco, têm a percepção intrauterina da presença do feto. As trajetórias masculina e feminina rumo à parentalidade são inegavelmente distintas devido às diferenças tanto biológicas como culturais (NOGUEIRA, 2011). Os pais costumam se sentir excluídos do processo devido a essas diferenças, que, por muito tempo, foram reforçadas pelos papéis sexuais (JAGER \& BOTTOLI, 2011; MALDONADO ET AL., 1985; PICCININI ET AL., 2009). Dessa forma, durante a gravidez muitos homens sentem-se perdidos, sem saber como interagir com o filho. Já que não podem participar diretamente das trocas com o feto que está sendo gestado, alguns pais buscam contribuir para o desenvolvimento fetal por meio da comunicação externa com o filho, conversando com a barriga da mãe, por exemplo (CAMPOS, 2006; RAPHAEL-LEFF, 1993).

Bornholdt et al. (2007), em pesquisa realizada com homens que vivenciavam a gravidez de seu primeiro filho, buscaram apreender a experiência da gestação à luz da perspectiva paterna. As autoras constataram que muitos pais têm dificuldades em estabelecer relação com seu filho durante a gestação, parecendo não percebê-lo como real. Também apareceu como resultado do estudo o desejo dos pais de participarem da gestação e do desenvolvimento dos filhos. Contudo, o sentimento de exclusão também esteve presente nas falas. Alguns pais referiram tal exclusão às diferenças entre os sexos, mencionando a "habilidade natural feminina" no cuidado com os filhos. Ao mesmo tempo, os pais apontaram diferentes formas de participação no processo gestacional, demonstrando que a gravidez é cada vez menos restrita ao universo feminino.

A construção da relação entre pai e bebê durante a gestação é estabelecida basicamente por meio da imagem mental que o pai constrói sobre o bebê e das interações entre ambos. Tal imagem mental tem relação tanto com fantasias e desejos inconscientes como com dados concretos, observados a partir dos movimentos fetais e dos exames médicos. A construção da imagem mental do bebê permite ao pai que o filho passe a integrar seu mundo psíquico desde a gestação (FERREIRA ET AL., 2014; MALDONADO ET AL., 1985; PICCININI ET AL., 2009).

Neste sentido, o contato com a pele da barriga da gestante, que favorece ao pai experienciar a resposta dos movimentos fetais, e a ultrassonografia, parecem ser recursos facilitadores da inclusão do pai na gestação, auxiliando o homem no desenvolvimento de uma imagem mental do bebê (PICCININI ET AL., 2009; RAPHAEL-LEFF, 1993). A ultrassonografia propicia a sensação de concretude do filho (BRANDÃO, 2009; FIGUEIREDO \& MARQUES, 2011; LEITE, RODRIGUES, SOUSA, MELO \& FIALHO, 
2014) e possibilita aos pais partilharem uma posição de igualdade, na medida em que pai e mãe têm acesso à mesma imagem do bebê e às mesmas informações simultaneamente (PICCININI ET AL., 2009). Cabe ressaltar que com o avanço na tecnologia dos aparelhos de ultrassonografia nos últimos anos, houve aumento significativo na definição das imagens, o que contribui para que o pai visualize uma imagem próxima de como será o seu bebê na realidade.

O exame pode estimular o interesse e o envolvimento dos pais (BRANDÃO, 2009), na medida em que a observação do feto em desenvolvimento geralmente facilita a vinculação paterna. Piccinini, Silva, Golçalves, Lopes \& Tudge (2004) constataram que o contato visual com o bebê, através da ultrassonografia, proporcionou aos pais por eles entrevistados a sensação de concretude em relação ao bebê, o que desencadeou reações positivas que contribuíram para o estabelecimento do vínculo pai-bebê.

Imaginar as características do bebê permite que ele se torne mais real e conhecido no psiquismo dos pais. Tal processo propicia uma associação com as experiências nas famílias de origem dos membros do casal, possibilitando a resolução ou a intensificação de conflitos entre os pais e seus próprios genitores, assim como a inserção do bebê na trama de fantasias familiares transmitidas entre as gerações. Em alguns casos, a reconexão do pai com seu passado, durante a gestação de sua parceira, pode produzir recombinações de sua personalidade, promovidas por reatualizações dos conflitos edípicos (CAMPOS, 2006; RAPHAEL-LEFF, 1993).

Apesar de a transição para a paternidade ser considerada uma mudança de extrema importância no ciclo vital, os estudos sobre parentalidade têm sido voltados, sobretudo, para a maternidade, e as experiências subjetivas dos pais estão apenas começando a ser exploradas. Neste sentido, o presente estudo pretendeu pesquisar as experiências subjetivas dos homens durante a gestação de suas parceiras, a fim de contribuir para as ações voltadas para a saúde masculina nesse momento do ciclo vital.

\section{Método:}

\subsection{Participantes:}

Foram entrevistados oito homens dos segmentos médios da população carioca, com idades entre 24 e 36 anos, que se tornaram pais há no mínimo dois meses e no máximo um ano, que coabitam com a mãe do bebê e residem na cidade do Rio de Janeiro. Cabe ressaltar que a definição de segmentos médios adotada no presente trabalho vai além do conceito de 
classe social pautada somente na renda familiar, correspondendo, portanto, a algo mais abrangente e complexo, pois considera aspectos como acesso ao conhecimento, escolaridade, capital cultural, entre outros (Velho, 1987).

Tabela 1: Perfil Dos Participantes

\begin{tabular}{|c|c|c|c|c|c|}
\hline Participante & Idade & Profissão & Sexo do bebê & Idade do bebê & $\begin{array}{l}\text { Tipo de } \\
\text { parto }\end{array}$ \\
\hline P1 & 31 & Médico & Menina & 3 meses & cesárea \\
\hline $\mathrm{P} 2$ & 35 & Advogado & Menino & 1 ano & cesárea \\
\hline P3 & 36 & Técnico-administrativo & menina & 4 meses & cesárea \\
\hline P4 & 34 & Professor e escritor & Menino & 7 meses & cesárea \\
\hline P5 & 33 & Administrador & Menina & 2 meses & $\begin{array}{l}\text { parto } \\
\text { vaginal }\end{array}$ \\
\hline P6 & 24 & Tradutor & Menina & 4 meses & $\begin{array}{l}\text { parto } \\
\text { vaginal }\end{array}$ \\
\hline P7 & 31 & Músico & Menina & 2 meses & $\begin{array}{l}\text { parto } \\
\text { vaginal }\end{array}$ \\
\hline P8 & 32 & Administrador & Menina & $\begin{array}{l}1 \text { ano e } \\
1 \text { mês }\end{array}$ & cesárea \\
\hline
\end{tabular}

Fonte: Pesquisa realizada pelas autoras.

Como instrumento de investigação, realizou-se com cada participante uma entrevista com roteiro semiestruturado, contendo questões abertas, composta pelos seguintes eixos temáticos: experiências subjetivas durante a transição para a paternidade; participação masculina nos cuidados com o filho; experiências corporais; redes de apoio.

\subsection{Procedimentos:}

Após aprovação do projeto de pesquisa pelo Comitê de Ética em Pesquisa da universidade onde foi desenvolvido, os participantes foram selecionados a partir de contatos informais em diferentes redes de sociabilidade da pesquisadora. As entrevistas tiveram duração média de 40 minutos, ocorreram entre dezembro de 2013 e maio de 2014 em locais 
de preferência dos participantes, e foram gravadas em áudio, com a devida autorização dos mesmos, mediante a assinatura de um Termo de Consentimento Livre e Esclarecido.

O material foi transcrito e submetido ao método de análise de conteúdo (BARDIN, 2011). Das falas dos entrevistados emergiram oito categorias de análise: mãe é mãe; ser pãe; demandas contraditórias: patriarca e cuidador; o homem grávido; ultrassonografia como ritual de passagem; o nascimento do pai; a construção de um vínculo; dos indivíduos à família. Para atingir o objetivo deste trabalho, foram discutidas as categorias o homem grávido e ultrassonografia como ritual de passagem, por estarem mais diretamente relacionadas às experiências subjetivas dos homens durante a gestação. As demais categorias foram discutidas em outros trabalhos divulgados.

\section{Resultados e discussão:}

Para a apresentação dos resultados, os pais foram nomeados de P1 a P8.

\section{O homem grávido:}

Durante a gestação, os sentimentos dos homens muitas vezes são desconsiderados devido ao fato de as transformações da gravidez ocorrerem no corpo das mulheres. Contudo, os pais também estão vivenciando transformações psíquicas que por vezes são expressas no corpo. Nas falas dos pais entrevistados não apareceu nenhum relato sobre a vivência de sintomas semelhantes aos da gestante, tampouco algum tipo de modificação em seus próprios corpos que lhes tenha chamado a atenção durante esse período. Porém, as noções de "casal grávido" e "homem grávido", já assinaladas por Maldonado et al. (1985) e Salem (1987/2007), permearam as falas dos sujeitos.

\footnotetext{
É uma coisa que as pessoas até normalmente perguntam, eu falo no plural "quando a gente estava grávido" (...) eu falo isso porque eu quero estar junto (P6).

Eu já vesti a camisa, e procurei aproveitar esse momento como se eu estivesse grávido, eu me senti grávido também um pouco (P3).
}

É possível que os homens entrevistados tenham vivenciado manifestações corporais ao longo da gestação e que estas tenham passado despercebidas por eles e por seu meio social. Como Parseval (1986) indica, há uma negação do corpo do pai na cultura ocidental, que pode dificultar ou até mesmo impossibilitar a ligação consciente entre os sintomas por eles apresentados durante a gestação e a transição para a paternidade, na medida em que tais vivências corporais não são autorizadas socialmente. 
Contudo, as recentes mudanças no papel do pai parecem abrir espaço para que os homens contemporâneos percebam e expressem cada vez mais seu desejo de gravidez e sua inveja da condição feminina, ampliando, dessa forma, as possibilidades de elaboração da inveja edípica. $\mathrm{O}$ desejo de engravidar e a frustração por essa impossibilidade apareceu na fala de um dos entrevistados:

Eu tinha vontade (de carregar o bebê dentro da barriga), difícil falar da concretude dessa vontade, mas... curiosidade. Porque a minha mulher ficava lá e eu botava a mão, tentava sentir o bebê e aquela curiosidade "pô, porque que eu não sinto?", eu não sei o que é isso, sabe? Eu acho que eu tinha muita curiosidade. E tinha vontade, sei lá, eu queria que os homens engravidassem também. Eu queria passar por isso, e eu não posso (P7).

Nesse sentido, se a inveja edípica se torna cada vez mais consciente, é possível que de fato esses pais não tenham experimentado no corpo a transição para a parentalidade, uma vez que conseguem transpor em palavras suas angústias, desejos e descontentamentos. Porém, apesar de participarem intensamente do processo da gestação, de se considerarem grávidos e relatarem seu desejo de gravidez, os pais entrevistados falaram sobre as diferenças entre homens e mulheres, marcando a forma como cada sexo vivencia a gestação e apontando para a inevitável sensação de exclusão, discutida nos estudos de Jager e Bottoli (2011), Maldonado et al (1985), Piccinini et al. (2009), Pincus e Dare (1978) e Zornig (2010).

Mas é aquela coisa diferente do homem pra mulher, eu tava ali do lado, e nela tava dentro. É diferente (P4).

Eu acho que o homem é um pouco refém assim nesse sentido. Em todos os sentidos. A partir do momento em que a mulher tá grávida o homem é um pouco refém, assim. Refém no sentido de que ele não determina como as coisas vão se dar sabe? Porque é o corpo da mulher e você vai remando na maré, sabe? (P7)

Eu fui em todos os exames com ela e tal, mas sei lá. Você vê a barriga crescendo, você sente os movimentos, você sabe que tem um bebê ali dentro, mas sei lá, ainda é um pouco distante, não é muito... apesar de saber que vai nascer daqui a pouco, você não tá vendo, você não tá participando muito ainda (P5).

Por não sentirem o bebê mexendo dentro de si, ou talvez por não poderem experimentar trocas diretas com o filho durante a gravidez, os entrevistados falaram sobre a distante concretude do filho durante a gestação. Porém, os homens/pais contemporâneos parecem buscar cada vez mais formas de participação no processo gestacional, seja por meio do contato com a pele da barriga da gestante com o intuito de experienciar os movimentos fetais, seja conversando com o feto, ou fazendo planos para o futuro do bebê.

Procurei curtir, dentro do possível, acompanhar, ver a barriga dela crescendo. E quando ele começou a chutar, começou a mexer, acho que esses foram os momentos mais bacanas desses nove meses (P2). 
A gente vivenciou essa expectativa juntos, a noite conversar com a barriga, fazer planos, a gente estava sempre fazendo planos, desde a escolha do nome, até o colégio onde estudaria... foi uma gravidez que a gente estreitou laços de parceria, de cumplicidade (P3).

A participação do homem desde o início da gestação é de extrema importância na preparação para o exercício da paternidade, pois possibilita aos pais a elaboração de fantasias e sentimentos referentes à sua própria infância e aos papéis parentais (BENAZZI ET AL., 2011; OLIVEIRA ET AL., 2009; PICCININI ET AL., 2004; SILVA ET AL., 2012). O envolvimento paterno na gestação propicia o exercício da paternidade antes do parto, colaborando para a vinculação precoce entre pai e filho (OLIVEIRA ET AL., 2009), além de possibilitar uma nova forma de vinculação com a mulher, contribuindo para a formação da parceria parental (FERREIRA ET AL, 2016). Nas falas dos entrevistados, o tempo da gestação apareceu como possibilidade de elaborar a paternidade, tanto por meio de ações concretas como montar o quarto do bebê ou preparar o enxoval, quanto por meio de conversas com familiares e preparações internas.

\footnotetext{
A gente planejou tudo direitinho, quarto do bebê, enxoval, não sei o que lá, aí eu fui pros EUA fazer o enxoval, pra comprar as coisas e tudo. (...) Eu fui sozinho, ela comprou tudo pela internet, mandou entregar e eu fui lá buscar com a minha mãe, eu e minha mãe a gente foi buscar, porque precisava de mala pra trazer (P8).

É um momento de construção. Construção de expectativas, de sonho, sabe? Eu acho que nesse momento da gravidez a gente se planejou pra montar um quarto pra ela, móvel e pintar o quarto e deixar tudo bonitinho. Acho que tem esses preparativos também (P7).
}

Uma vez a minha mãe falou isso: a gravidez não leva nove meses à toa, nesses nove meses a gente vai se preparando, a gente vai se acostumando com a ideia, a gente vai aprendendo... então, assim, são pequenas alegrias, pequenas novidades, pequenos sustos a cada dia, a cada semana uma nova coisa (P4).

Corroborando os resultados de Bornholdt et al. (2007), constatamos que os pais contemporâneos vêm apontando diferentes formas de participação na gestação, estando cada vez menos excluídos do processo. Os homens vêm sendo cada vez mais afetados pela gestação de suas parceiras, mesmo que tal envolvimento não seja expresso - ou percebido pela via do corpo. Nesse sentido, é possível que a reatualização da exclusão edípica seja mitigada a partir dos vários dispositivos contemporâneos que incluem os pais no processo gestacional, tais como construir o quarto do bebê, fazer o enxoval, e ter a participação no prénatal. Dessa forma eles iniciam o exercício da parentalidade e a vivência do casal parental já na gravidez. 


\section{Ultrassonografia como ritual de passagem:}

A ultrassonografia apareceu no discurso de todos os sujeitos entrevistados como um dos eventos de extrema importância na elaboração da transição para paternidade, sugerindo novas formas de ritualização das mudanças que estão se dando no psiquismo paterno nesse momento do ciclo vital.

A primeira ultra você não vê muita coisa, é só uma bolinha. Mas na segunda ultra já dá pra ver os dedinhos e tal. Aí você fica impressionado, é muito doido. Aí é que você realiza mesmo. É muito doido, é bem legal. Eu fico impressionado, porque é muito novo ainda, tem um centímetro e já tem tudo, você fica assim, muito impressionado mesmo (P5).

São várias ultras, então cada ultra é uma experiência. A primeira, vamos dizer, o coração batendo, é um caroço de feijão, mas é um coração. Você ouve o coração, então aquele caroço tá pulsando. Aquilo é muito forte! Aquilo é vida, é a primeira vez que fala VIDA. Aí depois tem aquelas de vai estar bem, vai ter doenças... você vai vendo o corpinho... (P4).

Cada ultra é um susto, uma coisa nova, uma emoção nova (P7).

Escutar o coração do bebê é muito maneiro! (P8)

Como apontado por Piccinini et al. (2009) e Raphael-Leff (1993), a ultrassonografia parece ser um recurso facilitador da inclusão do pai na gestação, na medida em que auxilia o homem a desenvolver uma imagem mental do bebê. Nas falas dos entrevistados, ficou evidente a contribuição do exame para o desenvolvimento dessa imagem mental.

Você fica ali ligado pra ver se tem cada detalhezinho, saber cada partezinha, cada dedinho, se tá tudo certinho, posição... mas é muito legal, por que a ultra mostra tudo, então a gente já via a fisionomia, já via os traços (P3).

Na ultra você vê, você entende melhor a parte que está maior na barriga é a bunda dela. E depois, tem uma coisa assim, fora da ultra você sabe que a sua filha ta ali, mas você vê também uma barriga, sabe? (...) Na ultra eu acho que tem uma coisa mais clara de "caraca é a minha filha!" Fora da ultra eu acho que era mais "pô eu sei que minha filha tá aí, de vez em quando ela soca, se expressa de alguma maneira, mas tem a barriga...” (P6).

(...) quando eu olhava, pode parecer idiota, mas quando eu olhava, a pessoa chegava e falava: "agora ela segurou o pé", aí eu: beleza, então ela tem mão e tem pé (P1).

A imagem mental do bebê tem relação tanto com fantasias e desejos inconscientes como com dados concretos, e permite ao pai que o filho passe a integrar seu mundo psíquico desde a gestação. A ultrassonografia, por proporcionar a visualização de uma imagem real do feto, propicia a sensação de concretude do bebê, como assinalado por Brandão (2009), Figueiredo e Marques (2011) e Maldonado et al. (1985). Os pais entrevistados relataram a sensação de concretude do filho proporcionada pela visualização do feto, chegando a levar 
consigo fotos impressas das ultras ou a afirmar seu desejo de ficar mais tempo nos exames para aproveitar a sensação de trocas diretas com o filho.

A gente fica vidrado na ultra pra observar cada detalhe, pra saber se aquele embriãozinho ali no início tá tudo bem, pra saber se está no tamanho adequado, no peso adequado, se os batimentos estão adequados (P3).

Algumas ultras o médico conseguia imprimir uma fotinho da imagem e eu andava na carteira $(\mathrm{P} 2)$.

Eu acho que era tipo eu to batendo um papo aqui com a minha filha. Eu lembro que eu ficava meio assim "pô não acaba não, eu quero ficar aqui, deixa esse sonzinho aí pra eu ouvir o coração dela, deixa a imagenzinha dela rolar". Eu lembro que ela sempre se mexia pra cacete. E minha mulher ficava "pô a gente já está há meia hora aqui, não dá pra ficar mais tempo, tem um negócio gelado em mim, está desconfortável". E eu falava "não, vamos ficar aqui, batendo papo com a nossa filha!" (P6).

A observação do feto em desenvolvimento geralmente facilita a vinculação precoce entre pai e bebê, estimulando o interesse e o envolvimento dos pais (BRANDÃO, 2009; PICCININI ET AL., 2004). A possibilidade de saber o sexo do bebê e antecipar algumas de suas características é, neste sentido, importante para a construção deste vínculo e apareceu nas falas dos sujeitos como um benefício da ultrassonografia.

Tinha uma ansiedade, também uma ansiedade por conta do sexo. Isso não tem nada a ver com saúde ou não, tem mais a ver com uma coisa minha particular. Eu tenho três irmãos, somos quatro homens, então esse excesso de masculino na minha vida... eu queria que fosse uma menina (P7).

A história de procurar saber o sexo do bebê, se vai ser menina ou vai ser menino, foi legal (P2).

Apesar de constituir-se como um recurso importante na elaboração da transição para a paternidade, a ultrassonografia foi também referida pela maioria dos entrevistados como um momento de tensão. Na medida em que permite aos pais se defrontarem com a imagem real do feto, parece gerar angústia pela possibilidade de o filho real que estão esperando ser diferente do filho por eles idealizado.

A gente esperava com ansiedade o momento da ultra, era uma coisa legal de fazer, mas tinha aquela tensão lá, né? Até a gente saber que estava tudo bem, confirmar que estava tudo certinho, era um momento de tensão (P3).

Mas eu acho que teve isso sim, não vou dizer que uma tensão porque é uma palavra muito forte, mas uma preocupação de estar tudo bem com o feto, de tá tudo tranquilo, assim (P7).

É engraçado porque pra mim a sensação é de que você nunca relaxa, né? Porque toda ultra que você vai não é nada pra ver coisa boa, é descobrir que não tem nenhum problema. Então você vai assim pra ver se realmente tá grávida (pô, tá grávida, legal!), aí vai pra ver se tem todos os...na morfológica, vai pra ver se não tem síndrome de não sei o que, então, pô, eu acho que eu só relaxei na ultra quando tava no final (P8). 
O medo de que o bebê tivesse alguma síndrome ou má formação permeou a fala dos entrevistados quando se referiam ao exame, apontando para a possibilidade de elaboração da passagem do filho idealizado para o filho real desde a gestação. A minha preocupação ao longo do tempo foi muito voltada pra isso, às más
formações, se ela tinha alguma trissomia, alguma coisa que pudesse gerar alguma
síndrome, ou alguma má formação cardíaca... (P1)

Era um pouco tenso assim no começo, no começo não, até o final. Porque eu não sabia... ficava um pouco preocupado do bebê ter alguma coisa, algum problema de saúde, sei lá. Você quer ter a segurança de que o bebê tá bem, de que tá tudo certo. De que a placenta tá toda certa, de que ele tá no peso ideal, no tamanho ideal. Então cada ultra você vai vendo lá, a gente entrava na internet e via qual era o peso ideal pra aquela idade de gestação (P7).

A cada ultra ver... na ultra cardiológica ver que o coração tá legal, na morfológica, ver que o risco de síndrome caiu, enfim, tudo isso me... nas ultras isso que me preocupava mais $(\mathrm{P} 1)$.

Por antecipar características do bebê, que outrora só podiam ser conhecidas no momento do nascimento, a ultrassonografia apareceu no discurso dos sujeitos como uma importante ferramenta de elaboração durante a transição para a paternidade. Tal importância atribuída ao exame parece apontar para uma forma de ritualização que marca essa etapa do ciclo vital própria das sociedades industrializadas contemporâneas.

\section{Considerações finais:}

As mudanças no papel feminino possibilitaram alterações também no lugar ocupado pelo masculino e vêm proporcionando a ampliação da participação paterna no âmbito do cuidado. Tal ampliação abre espaço para a verbalização de desejos até então impensáveis, como o desejo de gravidez por parte dos homens, por exemplo. Os homens/pais sem dúvida estão cada vez mais incluídos no processo da gestação, deixando-se atravessar pela gravidez, o que fica claro quando se autodenominam grávidos. Ao mesmo tempo, a autorização social para circular em um âmbito outrora restrito ao feminino, parece esbarrar nos limites do corpo. Não há autorização social para a vivência corporal da gravidez pelos homens, sendo notória a estranheza com a qual alguns entrevistados receberam a pergunta referente às mudanças no próprio corpo durante a gestação de suas parceiras.

O fato de os homens cada vez mais se deixarem incluir e requisitarem ampliação da sua participação na gestação desperta a atenção da sociedade para a gestação psíquica da parentalidade, ou seja, para a gestação que ocorre para além do corpo biológico. Durante a gestação é importante que os pais possam entrar em contato com conflitos infantis não 
elaborados, preparando-se para os novos papéis a serem desempenhados. Muitas mudanças ocorrem, sendo este um momento sensível também para os homens.

Nas sociedades industrializadas atuais, o ritual da couvade não se constitui em uma forma possível de elaboração das mudanças decorrentes da transição para a paternidade. No entanto, pensando no modo como a gestação é vivenciada em nossa cultura, certamente será possível encontrar outras formas de ritualização. No discurso dos sujeitos entrevistados, a ultrassonografia apareceu como uma ferramenta importante para a construção da imagem mental do bebê, constituindo-se, portanto, em um movimento elaborativo das mudanças que ocorrem no psiquismo dos pais. Neste sentido, parece ser uma forma de ritualização inerente a esta etapa de transição do ciclo vital própria das sociedades industrializadas atuais, marcadas pelo uso da tecnologia, pela valorização da imagem e pelo biocentrismo.

A concretude da ultrassonografia fez aflorar nos sujeitos ansiedades referentes ao estado de saúde do feto. Durante o exame, não foram experimentadas apenas vivências de gratificação e de alegria, ansiedade e medo também estavam presentes, associados principalmente à saúde do bebê. Talvez isso possa estar relacionado à ambivalência paterna decorrente da projeção de fantasias hostis em relação ao bebê. Porém, a partir dos resultados de nosso estudo, não foi possível o aprofundamento dessa questão. Nesse sentido, ressalta-se a importância do desenvolvimento de investigações futuras que abordem as ansiedades paternas relacionadas ao feto, abarcando as vivências de hostilidades e ambivalências na transição para a parentalidade.

Conclui-se ser de extrema importância que as políticas de saúde da família sejam voltadas também para os pais durante a gestação. Acreditamos que a oferta de uma escuta cuidadosa, que acolha as ambivalências, a inveja e o sentimento de exclusão dos pais, possibilite aos homens entrarem em contato com as transformações psíquicas vivenciadas durante a gestação de forma mais consciente. Sentindo-se acolhidos, é provável que busquem participar cada vez mais da gestação, do parto e da educação de seus filhos de forma mais ampla.

\section{PATERNAL PREGNANCY: A SUBJECTIVE EXPERIENCE}

\section{Abstract:}

The present article is part of a broader research about the transition towards fatherhood. The purpose of this study was to investigate the subjective experience of men during the pregnancy of their partners. In order to do so, the authors interviewed eight fathers living in the city of Rio de Janeiro. The authors transcribed and submitted the interviews to the content 
analysis method, using its thematic category mode. The results point towards the intensification of the involvement of fathers during the pregnancy, at the same time in which such participation clashes with the limitations of the body, thus, not allowing men to elaborate the changes caused by the transition towards parenthood through body rituals. Ultrasound imaging seems to be an important tool for the construction of the mental image of the baby, establishing itself as a possibility of elaboration of the changes that take place within the psyche of fathers.

Keywords: paternity; father; pregnancy; transition towards fatherhood.

\section{GESTACIÓN PATERNA: UNA EXPERIENCIA SUBJETIVA}

\section{Resumen:}

El presente artículo es parte de una investigación más amplia sobre la transición hacia la paternidad. El objetivo de este estudio fue investigar las experiencias subjetivas de los hombres durante la gestación de sus parejas. Para eso fueron entrevistados 8 padres, residentes en la ciudad de Río de Janeiro. Las entrevistas fueron transcritas y sometidas al método de análisis de contenido, en la modalidad categorial temática. Los resultados apuntan hacia la intensificación de la participación de los padres durante la gestación, al mismo tiempo en que tal participación se choca con los límites del cuerpo, no siendo posible para los hombres elaborar los cambios resultantes de la transición hacia la paternidad a través de ritualizaciones corporales. La ultrasonografía apareció como una herramienta importante para la construcción de la imagen mental del bebe, constituyéndose como posibilidad de elaboración de los cambios que ocurren en el psiquismo de los padres.

Palabras-clave: paternidad; padre; gestación; transición hacia la parentalidad.

\section{Referências:}

BARDIN, L. Análise de conteúdo. São Paulo: Edições 70, 2011.

BENAZZI, A.S.T., LIMA, A.B.S., \& SOUSA, A.P. Pré-natal masculino: um novo olhar sobre a presença do homem. Revista Políticas Públicas, vol. 15, n²2, 327-333, 2011.

BORNHOLDT, E.A., WAGNER, A., \& STAUDT, A.C.P. A vivência da gravidez do primeiro filho à luz da perspectiva paterna. Psicologia Clínica, vol. 19, nº 1, 75-92, 2007.

BRANDÃO, S. M. P. A. Envolvimento emocional do pai com o bebé: impacto da experiência de parto. Porto. [Dissertação de Mestrado]. Instituto de Ciências Biomédicas Abel Salazar/Universidade do Porto, 2009.

CAMPOS, L.P.L. As repercussões psicológicas da gravidez no pai. Mental, $n^{\circ} 7,147-160$, 2006. 
CÚNICO, S.D., \& ARPINI, M.D. A Família em Mudanças: Desafios para a Paternidade Contemporânea. Pensando Famílias, vol.17, n¹, 28-40, 2013.

FERREIRA, L.S., LEAL, I., \& MAROCO, J. Sintomatologia de couvade e o envolvimento paterno vivenciado durante a gravidez. Psicologia, Saúde \& Doenças, vol. 11, nº2, 251-269, 2010.

FERREIRA, A.D., MARTENDAL, M.L.N., SANTOS, C.M.S, BIROLO, I.V.B., \& LOPES, R. Participação do pai no nascimento: sentimentos revelados. Revista Inova Saúde, vol. 3, n'2, 16-36, 2014.

FERREIRA, I.S., LÔ, K.K.R., MELO, T.P., GOMES, A.M.F., ANDRADE, I.S. \& FERNANDES, A.F.C. Percepções de gestantes acerca da atuação dos parceiros nas consultas de pré-natal. Revista Rene, vol. 17, n³, 318-23, 2016.

FIGUEIREDO, M.G.A.V., \& MARQUES, A.C. Pré-natal: experiências vivenciadas pelo pai. Cogitare enfermagem, vol. 16, nº 4, 708-713, 2011.

GONÇALVES, L.S. \& BOTTOLI, C. Paternidade: a construção do desejo paterno. Barbarói, $\mathrm{n}^{\mathrm{o}} .48,185-204,2016$.

HOUZEL, D. As implicações da parentalidade. In: SOLIS-PONTON, L. (org.). Ser pai, ser mãe. Parentalidade: um desafio para o terceiro milênio (pp. 47-51). São Paulo: Casa do Psicólogo, 2004.

JAGER, M. E., \& BOTTOLI, C. Paternidade: vivência do primeiro filho e mudanças familiares. Psicologia: Teoria e Prática, vol. 13, nº1, 141-153, 2011.

LEITE, M.G., RODRIGUES, D.P., SOUSA, A.A.S., MELO, L.P.T., \& FIALHO, A.V.M. Sentimentos advindos da maternidade: revelações de um grupo de gestantes. Psicologia em Estudo, vol. 19, nº1, 115-124, 2014.

MALDONADO, M.T.; NAHOUM, J.C., \& DICKSTEIN, J. Nós estamos grávidos. Rio de Janeiro: Bloch, 1985.

MARTINI, T.A.D., PICCININI, C.A., \& GONÇALVES, T.R. Indicadores de síndrome de couvade em pais primíparos durante a gestação. Aletheia, nº 31, 121-136, 2010.

NOGUEIRA, J. R.D.F. As implicações do envolvimento do pai na gravidez/parto na ligação emocional com o bebé (pp. 29-32). Viseu. [Dissertação de Mestrado]. Escola Superior de Saúde de Viseu, 2011.

OLIVEIRA, S.C., FERREIRA, J. G., SILVA, P. M.P., FERREIRA, J. M., SEABRA, R. A., FERNANDO, V.C.N. A participação do homem/pai no acompanhamento da assistência prénatal. Cogitare Enfermagem, vol. 14, ${ }^{\circ}{ }^{1}$, 73-78, 2009.

PARSEVAL, G.D. A parte do pai. Porto Alegre: R\&PM, 1986. 
PICCININI, C.A., SILVA, M.R., GOLÇALVES, T.R., LOPES, R.S., \& TUDGE, J. O Envolvimento Paterno durante a Gestação. Psicologia: Reflexão e Crítica, vol. 17, nº3, 303314, 2004.

PICCININI, C.A., LEVANDOWSKI, D.C., GOMES, A.G., LINDENMEYER, D., \& LOPES, R.S. Expectativas e sentimentos de pais em relação ao bebê durante a gestação. Estudos de Psicologia, vol. 26, n³3, 373-382, 2009.

PINCUS, L., \& DARE, C. Psicodinâmica da família. Porto Alegre: Editora Artes Médicas Sul Ltda, 1978.

PRADO, J.C., \& ABRAÃO, J.L.F. Paternidade: um estudo sobre pesquisas desenvolvidas no contexto brasileiro. Colloquium Humanarum, vol.11, nº $1,2014$.

RAPHAEL-LEFF, J. Pregnancy: the inside story. London: Sheldon Press, 1993.

SALEM, T. O casal grávido: disposições e dilemas da parceria igualitária. Rio de Janeiro: Editora FGV, 2007. (Original publicado em 1987).

SILVA, E., LAMY, Z., ROCHA, L., \& LIMA, J. Paternidade em tempos de mudança: uma breve revisão da literatura. Revista Pesquisa em Saúde, vol. 13, n², 54-59, 2012.

SOIFER, R. Psicologia da gravidez, parto e puerpério. Porto Alegre: Artes Médicas, 1980.

VELHO, G. Individualismo e cultura. Rio de Janeiro: Jorge Zahar, 1987.

VIEIRA, M.L., BOSSARDI, C.N., GOMES, L.B., BOLZE, S.D.A., CREPALDI, M.A., \& PICCININI, C.A. Paternidade no Brasil: revisão sistemática de artigos empíricos. Arquivos Brasileiros de Psicologia, vol. 66, n², 36-52, 2014.

VIEIRA, G.T., \& NASCIMENTO, A.R.A. Aspectos psicossociais da construção da identidade paterna. Revista Psicologia: Teoria e Prática, vol. 16, nº1, 57-68, 2014.

VIEIRA, E.N., \& SOUZA, L. Guarda paterna e representações sociais de paternidade e maternidade. Análise Psicológica, vol. 28, nº 4, 581-596, 2010.

ZORNIG, S. Tornar-se pai, tornar-se mãe: o processo de construção da parentalidade. Tempo psicanalítico, vol.42, nº2, 453-470, 2010.

Data de recebimento: $30 / 12 / 2016$.

Data de aceite: 08/12/2017.

\section{Sobre as autoras:}

Mariana Gouvêa Matos é doutoranda em psicologia clínica pela PUC-Rio. Endereço Eletrônico: mariana.g.matos@hotmail.com

Andrea Seixas Magalhães é professora adjunta do Departamento de Psicologia da PUC-Rio. Endereço Eletrônico: andreasm@puc-rio.br 
Terezinha Féres-Carneiro é professora adjunta do Departamento de Psicologia da PUC-Rio. Endereço Eletrônico: teferca@puc-rio.br

Rebeca Nonato Machado é pós-doutoranda em psicologia clínica pela PUC-Rio. Endereço Eletrônico: recanm@gmail.com 